\title{
Speech by Chinese Premier Wen Jiabao at his meeting with the officers of the Executive Committee of the International Union of Geological Sciences
}

\author{
The Great Hall of the People, Beijing, China \\ 19th June, 2007
}

I am very glad to meet you all. As a geologist, I am pleased and gratified to have time to talk to you on geology. I will speak about three issues, and will be very happy if this is of some inspiration to you.

Firstly, the Chinese Government highly values the role of the International Union of Geological Sciences, and has actively supported its work. Through the Union, we hope to strengthen the friendly cooperation between geologists of China and other countries.

There are two sayings, which can probably be regarded as truths.

One is: "So long as the Earth on which we live exists, geological sciences will not only exist but unceasingly develop."

The other is: "Geological sciences and geological structures do not end at national boundaries. Working on the same planet, geologists need to communicate and share knowledge with each other, and to draw on each other's experiences."

Secondly, I have some ideas about the importance of contemporary geological sciences.
With the development of human economic society, the relationship between geology and humankind is becoming increasingly close. This is demonstrated chiefly by the human-nature relationship. As people, we can know nature correctly and live in harmony with it. In the past, the integral character of geology was displayed mainly by the combination of geology with younger sciences such as geophysics and geochemistry, and with technical tools such as remote sensing, drilling and testing. Today, these combinations seem highly inadequate. We need to integrate geology with studies of life, Earth's environments, the Solar System, and

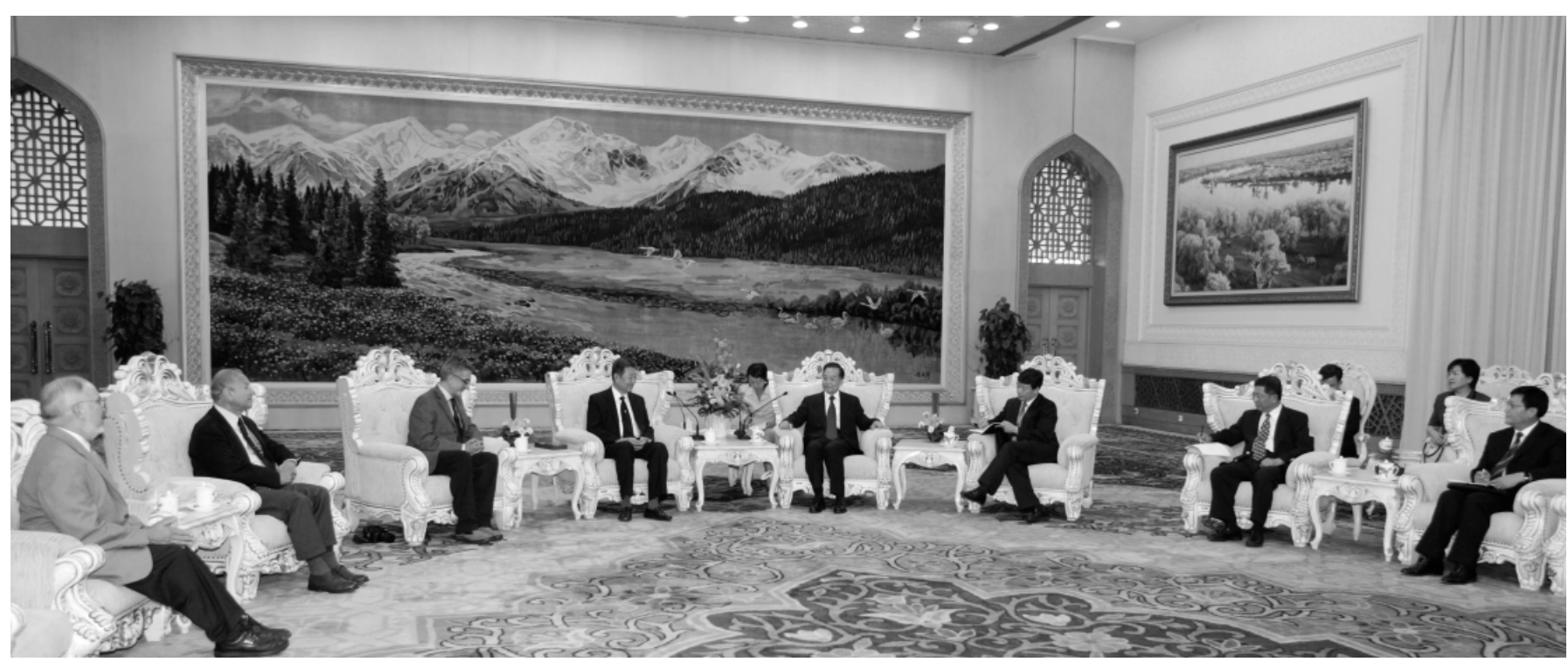

Chinese Premier Wen Jiabao meets with the officers of the Executive Committee of the International Union of Geological Sciences (IUGS). From left: Eldridge Moores (IUGS Vice President), Antonio Brambati (IUGS Treasurer), Peter Bobrowsky (IUGS Secretary General), Zhang Hongren (IUGS President), Premier Wen Jiabao, Xu Shaoshi (Minister of Land and Resources of China), Li Yuan (Vice Minister of Land and Resources of China), and Huang Zongli (Director of Department of International Cooperation, Science and Technology, Ministry of Land and Resources of China). 
all of space sciences. All life including humans, Earth and its environments, and celestial bodies combine to form one entirety.

We said in the past that geology had to study both the micro- and the macro-world, from outward appearance to inner essence. But these studies dealt only with the Earth itself. Now research areas of geological sciences extend from sub-microscopic particles to the macroscopic Universe. The scope of geology is not at all narrowed but vastly widened.

The intimate connection of the geosciences with the world's economies, societies and environments is manifested chiefly in the following aspects:

- Effecting rational development, utilization, protection, and conservation of natural resources in order to realize their sustainable use;

- Combating harmful climate and environmental changes by means of reducing emissions of greenhouse gases and other pollutants;

- Preventing and reducing damage caused by earthquake and other geohazards to the world and humankind;

- Achieving sustainable development of economies and societies; and

- Protecting our home - the planet Earth - upon which we rely for existence.

These are the challenges that modern geology is encountering; they are also the missions that keep modern geology vital to modern life.

Thirdly, I should like to introduce to you some development trends of geology in China, which I consider to be very important.

1. With regard to the relationship between continental China and global plate tectonics, two areas are especially noteworthy and involve new concepts: one is the active uplift of the Qinghai-Xizang Plateau; the other is the ancient ultrahigh-pressure metamorphic rocks in eastern China, where we have drilled a deep hole for geoscientific research in Lianyungang, Jiangsu Province. These studies of old and new tectonic structures have deepened our understanding of the continental dynamics of all of China.

2. The discoveries of the Chengjiang fauna and the Jehol biota mark major breakthroughs in the theory of organic evolution, touching upon the relationship between tectonics and organic changes.

3. China possesses the most widespread and thickest loess deposits in the world. Research on the environment during the formation of loess, its relationship with the evolution of paleoclimate, the conditions of karst development, and the history of carbon cycle changes in the Earth's environments have all contributed to our understanding of modern climatic change.

The above three points that I have mentioned are issues that are important to our fundamental understanding of geology. In another respect, we need to pay further attention to natural resources, particularly energy resources. Recently a large oil-gas field was discovered in Nanpu, Hebei Province. I was very happy to hear the news, because I suggested many years ago that it was important to strengthern oil-gas exploration in Bohai Bay. In my opinion, the Bohai Bay area has great potential. The basin being drilled is the smallest one among a series of basins. There are many larger basins in the surrounding area. Why were they not found in the past? Formerly, the accuracy of geophysical prospecting was inadequate and drilling reached merely 1,000 to $2,000 \mathrm{~m}$ depths. Now the situation has changed. By using 3-D seismic surveys and with the ability to drill to depths to as much as 3,000 to $4,000 \mathrm{~m}$, the hydrocarbon reservoir was finally revealed. In my view, the exploration and production of natural gas in China will become increasingly important.

We are pleased with the discovery of the oil-gas field, but at the same time, we emphasize energy conservation. While laying equal stress on both exploration and conservation, both of which are important, conservation takes precedence.

Coal-bed methane occurs in many coalfields in China. Coal-bed methane is harmful, but it may be useful when utilized properly. We lack experience and tools in this field.

There are a variety of hazardous geological events that have occurred in China. Earthquakes happen frequently, and during rainy seasons, landslides and mudflows cause many casualties.

Therefore, as a geologist, I often think deeply over life, the Earth, and celestial bodies, and I care about the vital problems of resources and environment. As a leader, I must adhere to the scientific concept of development, which is human-oriented, comprehensive, coordinated and sustainable. I must always bear in mind that China has a large population but limited land, water, energy and other resources. Today, our ecological environment is under tremendous pressure. It is imperative that we develop and use our resources rationally, work to protect the ecological environment, cherish every forest, every river, every square centimeter of land, and every mining locality. We need to pursue a resourceeconomizing and ecologically-friendly way of development, so that humanity may live in harmony with nature forever. 